\title{
Crosstalk between Vitamins A, B12, D, K, C, and E Status and Arterial Stiffness
}

\author{
Ioana Mozos, ${ }^{1}$ Dana Stoian, ${ }^{2}$ and Constantin Tudor Luca ${ }^{3}$ \\ ${ }^{1}$ Department of Functional Sciences, Discipline of Pathophysiology, "Victor Babes" University of Medicine and Pharmacy, \\ Timisoara, Romania \\ ${ }^{2} 2$ nd Department of Internal Medicine, "Victor Babes" University of Medicine and Pharmacy, Timisoara, Romania \\ ${ }^{3}$ Department of Cardiology, "Victor Babes" University of Medicine and Pharmacy, Timisoara, Romania
}

Correspondence should be addressed to Dana Stoian; stoian.dana@umft.ro

Received 8 October 2016; Accepted 14 December 2016; Published 12 January 2017

Academic Editor: Ying Huang

Copyright (c) 2017 Ioana Mozos et al. This is an open access article distributed under the Creative Commons Attribution License, which permits unrestricted use, distribution, and reproduction in any medium, provided the original work is properly cited.

\begin{abstract}
Arterial stiffness is associated with cardiovascular risk, morbidity, and mortality. The present paper reviews the main vitamins related to arterial stiffness and enabling destiffening, their mechanisms of action, providing a brief description of the latest studies in the area, and their implications for primary cardiovascular prevention, clinical practice, and therapy. Despite inconsistent evidence for destiffening induced by vitamin supplementation in several randomized clinical trials, positive results were obtained in specific populations. The main mechanisms are related to antiatherogenic effects, improvement of endothelial function (vitamins A, C, $\mathrm{D}$, and $\mathrm{E}$ ) and metabolic profile (vitamins $\mathrm{A}, \mathrm{B} 12, \mathrm{C}, \mathrm{D}$, and $\mathrm{K}$ ), inhibition of the renin-angiotensin-aldosterone system (vitamin D), anti-inflammatory (vitamins A, D, E, and K) and antioxidant effects (vitamins A, C, and E), decrease of homocysteine level (vitamin B12), and reversing calcification of arteries (vitamin K). Vitamins A, B12, C, D, E, and K status is important in evaluating cardiovascular risk, and vitamin supplementation may be an effective, individualized, and inexpensive destiffening therapy.
\end{abstract}

\section{Introduction}

Cardiovascular diseases are the main cause of mortality worldwide and prophylactic measures deserve special attention. Arterial stiffness, one of the earliest detectable signs of structural and functional changes of the vessel wall [1], is associated with cardiovascular risk, morbidity and mortality, atherosclerosis and arteriosclerosis, aging, and several chronic disorders. Measurement of pulse wave velocity (PWV) is a simple, noninvasive, validated, the most used, and reproducible method to assess arterial stiffness [2]. A recently published meta-analysis, including 17,635 participants, demonstrated that an increase of PWV of $1 \mathrm{~m} / \mathrm{s}$ is associated with a 7\% increased risk of subsequent cardiovascular events, concluding that aortic PWV enables identification of high cardiovascular risk subjects, that might benefit from more aggressive risk factor management [3]. Augmentation index, a measure of peripheral arterial reflective properties, is also a complex and indirect marker of arterial stiffening $[4,5]$.
A $10 \%$ increase in the augmentation index was associated with $31.8 \%$ increased risk of cardiac events [6].

Aging and several disorders cause degenerative changes of the vessel wall of large arteries, related to the rupture of the elastic fibers, impaired cross-linking of extracellular matrix components, accumulation of collagen, fibrosis and necrosis of muscle fibers, inflammation, and calcification, leading to their stiffening $[7,8]$. Vascular calcification, calcium phosphate complexes deposition in the arterial wall, is an active process, enabled by several mechanisms, and leads also to loss of arterial wall elasticity and an increased PWV, related to vascular remodeling, organ damage, and overall morbidity and moratlity $[9,10]$. It can be present as medial calcification (Monckeberg's medial sclerosis, prevalent among patients with diabetes and renal and hyperparathyroid disorders) or intimal calcification (on the surface of the atherosclerotic plaque) [11]. Hypertension, inflammation, oxidized low density lipoproteins, and a high calcium-phosphorus ion product enable transformation of vascular smooth muscle 
cells into osteocyte-like cells $[12,13]$. Functional deterioration of the arteries involves reduced bioavailability of $\mathrm{NO}$ and endothelial dysfunction [1]. Reduction of arterial compliance causes a faster reflection of the systolic wave from the peripheral arteries to the heart, increasing the central aortic pressure and causing myocardial hypertrophy and ischemia [1].

Destiffening is a challenge of cardiovascular prevention and deserves special attention. Diet is a modifiable cardiovascular risk factor [14] and Mediterranean diet and nutrients with antioxidant and anti-inflammatory properties may improve vascular function, despite contradictory findings of randomized trials [15-17].

There is a worldwide trend toward nutritional insufficiency [18], related to aging of the population, with changes of anatomy and function of the kidney. Socioeconomic improvement has been associated with nutritional changes and increased prevalence of cardiometabolic disorders [19]. Dietary factors may accelerate or slow the evolution of cardiovascular disorders. Dietary vitamin supplements, easily accepted and often used by Western populations, may provide potential benefits and harms related to their use [20].

Considering the worldwide trend toward nutritional insufficiency, it was the aim of the present paper to review the main vitamins related to arterial stiffness and enabling destiffening, their mechanisms of action, including a brief description of the latest studies in the area, and their implications for primary cardiovascular prevention, clinical practice, and therapy.

\section{Vitamin D}

Vitamin D, "the sunshine vitamin," is known especially for promoting calcium deposition in bones. Vitamin D receptors have been found in several other tissues, including vascular smooth muscle, endothelial cells, and cardiomyocytes [27]. Vitamin D deficiency is very common, due to indoor lifestyle, sun avoidance strategies, air pollution, and smoking, is often unrecognized or untreated, and is associated with increased all-cause mortality and cardiovascular event rate [28] and linked to major cardiometabolic risk factors, including obesity, hypertension, and diabetes mellitus [50]. Unfortunately, it is also very common during perinatal period, linked not just with poor bone development, but also with heart disease, type 1 diabetes mellitus, and cancer [51, 52]. Vitamin D deficiency activates the renin-angiotensin-aldosterone system, and the increased vascular tone, due to release of angiotensin II, and arterial stiffness precede the development of hypertension [53]. Vitamin D has also pleiotropic effects on the immune system and suppresses the low grade inflammation in the cardiovascular system, downregulating Th1 activity and dendritic cell maturation, inhibiting production of cytokines, and upregulating Th17 regulatory activity and modulating macrophage activity $[28,54,55]$.

Usually 25 hydroxy vitamin $D$ and not 1,25 dihyrdoxy vitamin $\mathrm{D}$ is assessed. 25 hydroxy vitamin $\mathrm{D}$ is the nutritional parameter of vitamin D status, the primary circulating and storage form of vitamin $\mathrm{D}$ in the human body, a reliable, available marker of low vitamin D levels, easy to administer, with few side effects, and able to bind to vitamin $\mathrm{D}$ receptors $[5,28]$. In the Whitehall study, the optimal concentration of $25(\mathrm{OH})$ vitamin $\mathrm{D}$ was $80-90 \mathrm{mmol} / \mathrm{l}$ and a linear, inverse association of vitamin $\mathrm{D}$ level with both vascular and nonvascular mortality was reported [56].

The role of vitamin D deficiency in vascular disease is an emerging issue [18]. Several studies revealed associations between vitamin D level and PWV [5, 57-60], but other authors found no significant association between vitamin $\mathrm{D}$ concentrations and markers of subclinical atherosclerosis $[61,62]$. The effect of vitamin D supplementation on arterial stiffness showed also conflicting results, either beneficial or not (Table 1). Daily 2,000 IU vitamin D supplementation for 16 weeks resulted in a significant decrease in carotidfemoral PWV in 25 normotensive black boys and girls [33]. A significant decrease of arterial stiffness was also noticed after a single dose of 300,000 IU of cholecalciferol in children with chronic kidney disease [22]. Zaleski et al. reported a decrease of arterial stiffness with high-dose vitamin D supplementation for 6 months, and no effect on blood pressure [24]. The pleiotropic beneficial effects of vitamin $\mathrm{D}$ on arterial stiffness were suggested to be dose-dependent, which could explain the conflicting results of different studies [24]. McGreevy et al. found a significant decrease in augmentation index after 100,000 IU of vitamin D3 (the high-dose group) for 8 weeks, in older adults with vitamin D deficiency [25]. Forouhi et al. showed a modest reduction in PWV after D2 and D3 supplementation [21]. Ryu et al. found no beneficial effect of high-dose vitamin D supplementation on cardiovascular risk factors, PWV, or augmentation index in diabetic patients [27] and the same lack of change was reported by Chitalia et al. in predialysis chronic kidney disease patients [28]. Six months of vitamin D supplementation did not decrease central blood pressure parameters or arterial stiffness in healthy postmenopausal native American women [26]. A recent meta-analysis of randomized controlled trials concluded inconsistent evidence for destiffening induced by vitamin D supplementation, attributable to the heterogenity of the included studies [63].

Vascular calcification in the coronary or peripheral arteries is a powerful predictor of cardiovascular morbidity and mortality, linked to PWV [10], especially in hemodialysis patients [64]. High concentrations of vitamin D enable increased gastrointestinal calcium absorption, resulting in higher circulating calcium concentrations and increasing the number and size of calcification foci, resulting in vascular calcification, especially in atherosclerotic plaques $[9,62,65]$. Sachs et al. observed associations of lower concentration of vitamin $\mathrm{D}$ metabolites with reduced coronary artery calcium prevalence and severity, measured by computed tomography, in patients with type 1 diabetes mellitus [61]. A mouse model of chronic kidney disease revealed protective effect against aortic calcification at low vitamin D3 doses, sufficient to correct secondary hyperparathyroidism (higher doses stimulated aortic calcification) [66].

The main pathophysiological vasculoprotective mechanisms by which vitamin $\mathrm{D}$ supplementation reduces arterial stiffness include decrease of the renin-angiotensin-aldosterone system activity, suppression of endothelin-induced 

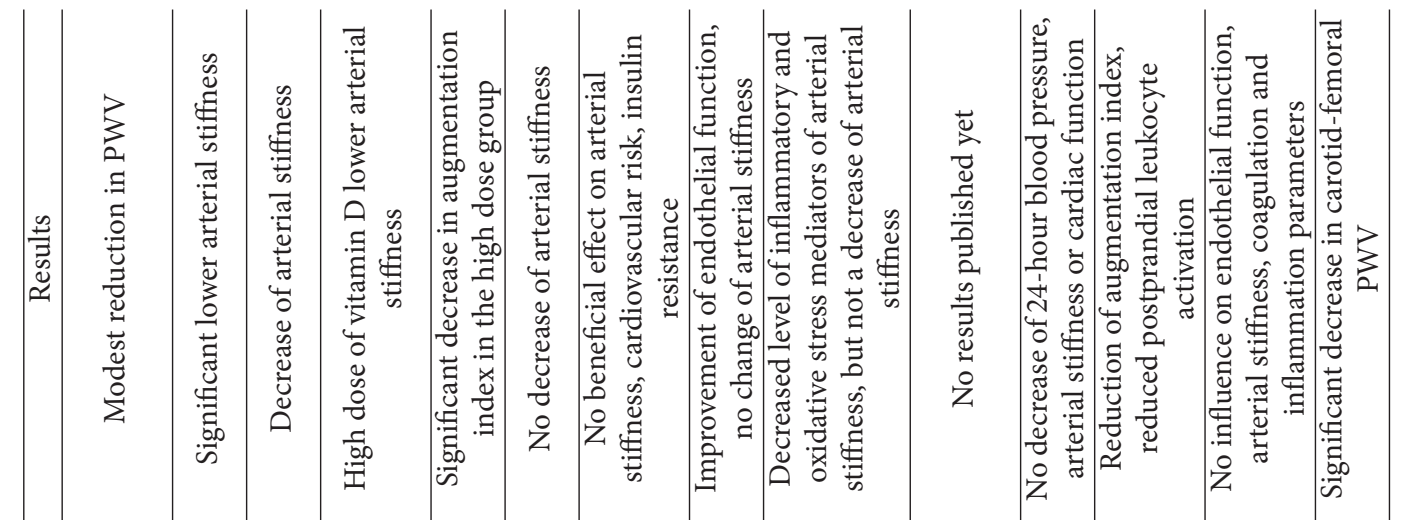

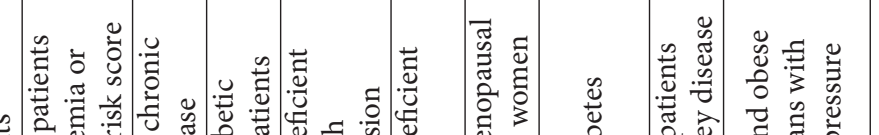

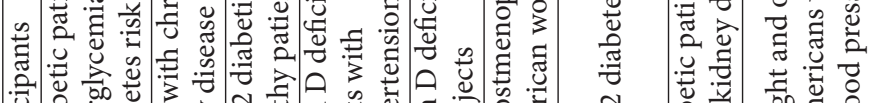

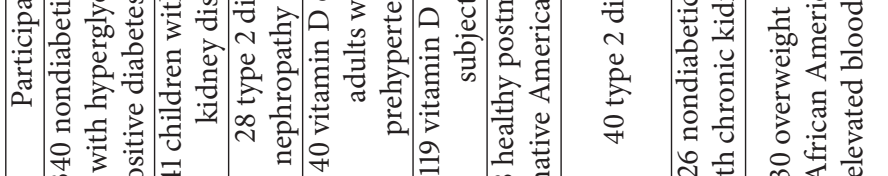

造

焉

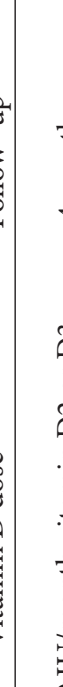

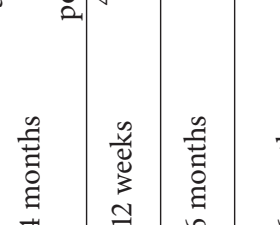

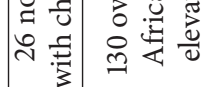

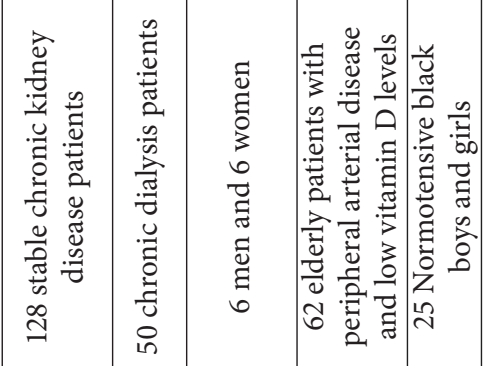

咅

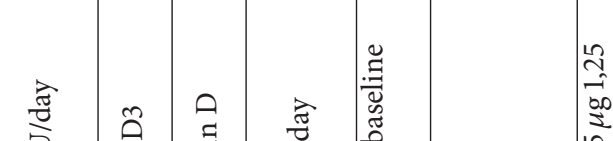

ind

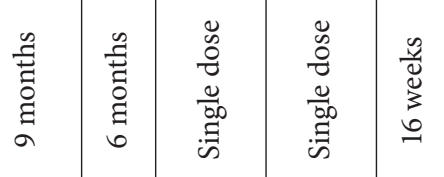

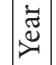
¿

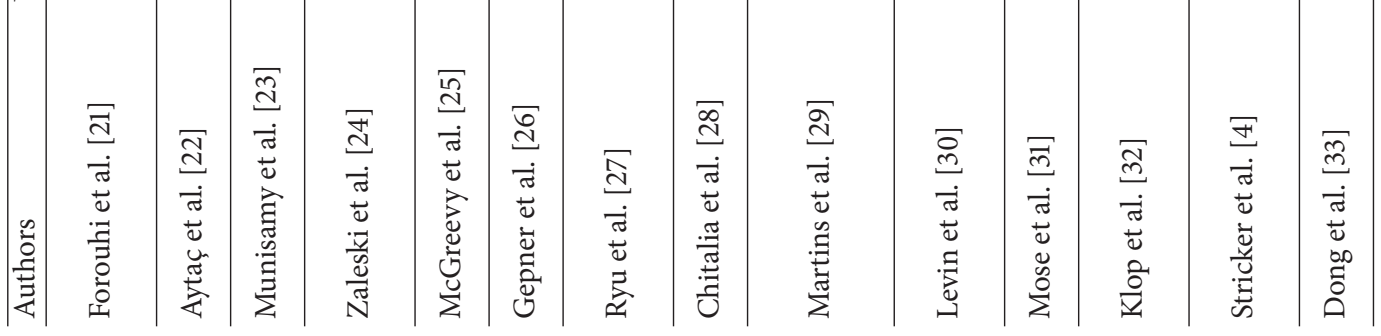


vascular smooth muscle cell proliferation, renoprotective effects, effects on calcium metabolism and PTH level, counterbalance of inflammation and oxidative stress, and improvement of carbohydrate metabolism and insulin sensitivity [24, 29, 33, 67, 68]. Fibroblast growth factor 23 (FGF-23), a circulating peptid secreted by bone cells, known for inducing phosphaturia, lowering 1,25 dihydroxy-vitamin $\mathrm{D}$, and suppressing PTH secretion, a new marker of inflammation, insulin resistance, and visceral fat accumulation, has been also associated with cardiovascular events and arterial stiffness $[50,69]$. FGF-23 acts on the vascular function through its coreceptor Klotho, which increases nitric oxide availability and it has also been related to the presence of vascular calcifications $[50,70]$. Low levels of vitamin $\mathrm{D}$ were associated with increased activity of matrix metalloproteinases and $\mathrm{C}$ reactive protein, correctable by supplementation [71].

The inconsistencies of vitamin D supplementation trials could be attributable to heterogeneity in vitamin $\mathrm{D}$ dosage, compounds and baseline concentration, study duration, design, population and follow-up, lack of a control group with normal vitamin $\mathrm{D}$ level, biases due to different comorbidities, therapy known to affect arterial stiffness, and several other confounding factors [24, 72]. Further large, longer duration, controlled randomized studies are required in order to demonstrate a causal relationship between vitamin $\mathrm{D}$ supplementation and decrease of arterial stiffness and to understand the importance of maintaining vitamin $\mathrm{D}$ sufficiency. There is no consensus on optimal levels of vitamin $\mathrm{D}$ in order to provide a beneficial cardiovascular effect, and this will be the aim of future clinical trials.

\section{Vitamin $\mathrm{K}$}

Vitamin K, a lipid-soluble vitamin, is an essential micronutrient. It includes vitamins $\mathrm{K} 1, \mathrm{~K} 2$, and K3. Phylloquinone (vitamin $\mathrm{K} 1$, phytonadione) is found especially in dark-green leafy vegetables and seeds, and menaquinone-7 (Vitamin K2), formed mostly by bacteria, may be obtained from meat, eggs, and fermented cheese $[11,73]$. Vitamin K3 (menadione) is a synthetic vitamin $\mathrm{K}$.

Vitamin $\mathrm{K}$ is essential for blood coagulation, but vitamin $\mathrm{K}$ insufficiency was associated also with an increased risk of cardiovascular events in healthy middle-aged people, type 2 diabetes, and end-stage renal disease patients [34]. Observational studies revealed a lower prevalence of arterial calcification and cardiovascular mortality in subjects with a high intake of menaquinones (vitamin K2) and no effect for phylloquinone (vitamin K1) [35, 74, 75]. An accelerated progression of aortic stiffness, associated with the use of warfarin, has been demonstrated in a study including 18 hemodialysis patients [76]. Vitamin $\mathrm{K}$ antagonists inhibit the recycling of vitamin $K$ in the epoxide cycle, reduce carboxylation of coagulation factors, and cause calcifications in several arteries and valves [11]. Progression of aortic stiffness was related to the severity of vitamin $\mathrm{K}$ deficiency, assessed using circulating PIVKA-II, the undercarboxylated level of prothrombin and a sensitive subclinical vitamin $\mathrm{K}$ deficiency marker [76]. Matrix Gla-protein (MGP) is an inhibitor of soft tissue calcification; in its mature, active form it contains five Gla-residues (resulting from vitamin $\mathrm{K}$-dependent gamma-carboxylation of the respective Glu-residues) and three phosphoserine residues $[11,76,77]$. The inactive form, desphospho-uncarboxylated MGP (dp-ucMGP) is regarded as a sensitive marker for vascular vitamin $\mathrm{K}$ status and increased levels of plasma dpucMGP are associated with increased cardiovascular and allcause mortality $[11,35,78]$. As calcification develops, MGP is upregulated in vascular smooth muscle cells, as a negative feed-back mechanism [11, 79]. Pivin et al. found a positive association between PWV and inactive MGP, before and after adjustment for common cardiovascular risk factors and renal function [80]. Mayer Jr. et al. confirmed the relationship between inactive MGP and aortic stiffness, after adjusting for all potential confounders, but not with stiffness of musculartype arteries [81]. MGP levels were not predictors for carotidfemoral pulse wave velocity in renal transplant recipients [82]. Vitamin K-dependent proteins, requiring carboxylation to become biologically active, contribute to thrombus formation, vascular calcification, vascular stiffness, and ischemic cardiovascular events [11, 83].

A possible role of vitamin $\mathrm{K}$ in suppressing chronic inflammation and reversing calcification of arteries was suggested [34]. Observational studies have shown an inverse association between vitamin $\mathrm{K}$ status and inflammatory markers, such as interleukin- 6 and $\mathrm{C}$ reactive protein $[35,84]$. Vitamin $\mathrm{K}$ might suppress inflammation by decreasing expression of genes for cytokines [85]. Warfarin may impair pulse pressure in patients with a history of hypertension and higher cardiovascular risk [86], contributing to progression of arterial stiffness. Vitamin $\mathrm{K} 2$ has also the ability to improve lipid profile by increasing HDL cholesterol and decreasing total cholesterol [74].

Induction of type 1 diabetes mellitus, in rats with streptozotocin, resulted in augmentation of arterial stiffness, increase of aortic and femoral calcifications, and reduction of $\gamma$-carboxylated MGP (the active form of MGP) [8]. Reduced MGP is involved in the early development of medial artery calcification (MAC) in diabetes and the deposition of hydroxyapatite crystals along the large arteries, resulting in accelerated arterial stiffness [8].

A correlation between PWV and aortic calcium content has been previously demonstrated in a warfarin-vitamin $\mathrm{K}$ rat model of MAC [7]. Increased vitamin K2 intake has been associated with decreased arterial calcium deposition and the ability to reverse vascular calcification in animal models [10]. Vaccaro and Huffman found an inadequate vitamin K1 intake in older adults, especially in Hispanic and Black Americans, and vitamin $\mathrm{K} 1$ was an independent predictor of high arterial pulse pressure [87].

Daily supplementation with oral vitamin K2 for 6 months caused a modest, nonsignificant improvement in PWV in older patients with vascular disease [34] (Table 2). Long-term supplementation with $180 \mu \mathrm{g}$ menaquinone/day for three years decreased arterial stiffness in healthy postmenopausal women, especially in women with a high arterial stiffness [35]. Spronk et al. fed warfarin-treated rats diets containing vitamins $\mathrm{K} 1$ or $\mathrm{K} 2$ and found that just menaquinone inhibits warfarin-induced arterial calcification, explained by its more 
TABLE 2: Effect of vitamin K supplementation and arterial stiffness in human subjects.

\begin{tabular}{lccccc}
\hline Authors & $\begin{array}{c}\text { Year of } \\
\text { publication }\end{array}$ & Follow- up & Dose of vitamin K & Study population & Results \\
\hline Fulton et al. [34] & 2016 & 6 months & $\begin{array}{c}\text { Oral 100 mcg vitamin } \\
\text { K2 }\end{array}$ & $\begin{array}{c}\text { Participants aged } \leq 70 \text { years, } \\
\text { with a history of vascular } \\
\text { disease }\end{array}$ & $\begin{array}{c}\text { A modest nonsignificant } \\
\text { decrease in pulse wave } \\
\text { velocity (PWV) }\end{array}$ \\
\hline Knapen et al. [35] & 2015 & 3 years & $180 \mu \mathrm{g}$ menaquinone & 120 healthy & $\begin{array}{c}\text { carotid-femoral PWV and } \\
\text { the stiffness index } \beta \\
\text { decreased }\end{array}$ \\
\hline Vossen et al. [36] & 2015 & 24 months & $\begin{array}{c}360 \text { microgram } \\
\text { menaquinone-7 } \\
\text { (MK-7) }\end{array}$ & $\begin{array}{c}\text { Patients with coronary } \\
\text { artery disease }\end{array}$ & $\begin{array}{c}\text { Difference in coronary } \\
\text { artery calcification score } \\
\text { between MK-7 and control } \\
\text { group }\end{array}$ \\
\hline
\end{tabular}

effective utilization in the aorta [88]. The VitaK-CAC trial will explore the effect of menaquinone-7 supplementation on progression of coronary artery calcification in a randomized trial [36].

Concluding, vitamin $\mathrm{K}$, especially $\mathrm{K} 2$, enables destiffening by impairing and reversing calcification of arteries, suppressing the inflammatory reaction in the vascular wall and improving the lipid profile. Additional intake of vitamin K2 does not increase procoagulant activity or thrombosis risk because the blood coagulation factors are fully carboxylated [35].

\section{Vitamin E}

Vitamin E, the most abundant fat soluble antioxidant in the human organism, is found in high concentrations in palm oil, rice ban, and oily plants $[41,89]$ and includes tocopherols and tocotrienols. Plasma concentrations of vitamin E depend on the amount of plasma lipids and LDL cholesterol, considering that the latter is the main plasma carrier of tocopherol [90]. There is no generally accepted recommendation for an adequate intake of vitamin E [89]. Concentrations of vitamin $\mathrm{E}$ are influenced by age, lifestyle factors, such as obesity, smoking, alcohol consumption, fat malabsorption, interindividual differences in vitamin $\mathrm{E}$ metabolism, and interaction with pharmaceuticals (vitamin K, statins) [89].

Dietary intake of alpha-tocopherol, the main component of vitamin E, may reduce the cardiovascular risk [91, 92]. The antiatherogenic role of vitamin $\mathrm{E}$ has been suggested by its ability to decrease LDL oxidation [91, 93], quench free radicals, inhibit protein kinase $C$ (PKC), inhibit expression of adhesion molecules and monocyte transmigration [47, 94], and impair vascular smooth muscle cell proliferation [93]. $\mathrm{PKC}$ is a key mediator of the vasoconstrictor response to oxidative stress [95], and the inhibition of PKC is another mechanism enabling improvement of vascular endothelial function besides the antioxidant action [47]. Vitamin E may become prooxidant at high doses, in the absence of an effective cooxidant, enabling production of alpha-tocopheroxyl radical, which can be inhibited by coantioxidants such as vitamin $C[46,96,97]$. Vitamin $C$ reverses the prooxidant state of vitamin $\mathrm{E}$, supporting the combined administration of vitamins $\mathrm{C}$ and $\mathrm{E}[98,99]$. But vitamin $\mathrm{C}$ can become prooxidant as well [98]. Human studies did not confirm a reduction of oxidative stress biomarkers due to combined administration of vitamins $\mathrm{E}$ and $\mathrm{C}$, and the synergistic effects of the two vitamins disappeared under anaerobic conditions and became prooxidant [99]. Vitamin E has also anticoagulant properties by interfering with vitamin $\mathrm{K}$ dependent clotting mechanisms not related to its antioxidant effect [89].

Conflicting results have been obtained regarding effectiveness of vitamin $\mathrm{E}$ in reducing atherosclerosis progression or lipid lowering effect [41]. Vitamins E and C increased the collagen content of the arterial wall and reduced vascular metalloproteinase-1, stabilizing the atherosclerotic plaque in a porcine model of atherosclerosis [100]. Antioxidant vitamins inactivate free radicals, increase plasma and tissue antioxidant defense, reduce inflammation, inhibit DNA oxidation by $\mathrm{H}_{2} \mathrm{O}_{2}$ in human lymphocytes, and restore endothelial function $[16,101,102]$.

Hampson et al. found significant associations between PWV and alpha-tocopherol/gamma-tocopherol ratio, but not with alpha-tocopherol and gamma-tocopherol, in a crosssectional study, including 278 postmenopausal women, in a multilinear regression model, adjusted for lipids, age, and blood pressure, emphasizing the importance of the balance between the two vitamin $\mathrm{E}$ isomers in maintaining arterial compliance [103].

Short term supplementation with 1,000 IU of vitamin E improved endothelial function but not systemic arterial compliance in young patients with type 1 diabetes mellitus [47]. The improvement in endothelial vascular function was related to a reduction of LDL oxidation [47], and there is evidence that oxidized LDL might inactivate endothelial cell derived relaxing factor [104]. The endothelium, through the generation of vasoactive mediators (NO and endothelin), might influence arterial stiffness [105]. Wigg et al. demonstrated improved endothelium-dependent and independent vasodilation in mesenteric arteries from diabetic rats, associated with PKC, after vitamin E, independent of advanced glycation end-product accumulation [106]. In the femoral artery, vitamin E prevented the wall stiffening associated with diabetes [106]. The benefit may be due to a direct effect of vitamin $\mathrm{E}$ on smooth muscle function as a consequence of inhibition of PKC- $\beta 2$ isoform and due to improved NO availability in the smooth muscle [106]. Vitamin E supplementation significantly improved the endothelial function, despite 
heterogeneity of the studies, especially in study participants with a lower baseline plasma vitamin $\mathrm{E}$ concentration (less than $20 \mu \mathrm{M}$ ), and did not depend on age, vitamin E dose, and duration of supplementation [99].

Rasool et al. used low, medium, and high doses of vitamin $\mathrm{E}$ as self-emulsifying tocotrienol rich vitamin $\mathrm{E}$, for 2 months, in 36 healthy men and reported a significant reduction of PWV and augmentation index for the groups 100 and $200 \mathrm{mg}$, and no change in blood pressure, serum total, and LDL cholesterol [41]. A systematic review and meta-analysis revealed a small protective effect of antioxidant vitamins (vitamins $\mathrm{C}, \mathrm{E}, \mathrm{A}$, and beta-carotene) on arterial stiffness, especially in younger healthy participants compared to those with cardiometabolic disease, more important in subjects with lower baseline plasma level of vitamins $\mathrm{C}$ and $E$ [102]. The beneficial effects of the combined treatment with antioxidant vitamins $\mathrm{C}$ and $\mathrm{E}$ are due to the reduction of the damaging effects of free radicals on the vascular components and the anti-inflammatory effect, increasing the bioavailability of NO, improving endothelium-dependent vasodilation, and decreasing arterial stiffness and protecting the integrity of the vascular wall $[43,102]$. The rate constant of the reaction of antioxidant vitamins and superoxide is lower than that of the reaction between $\mathrm{NO}$ and superoxide, which makes the antioxidant vitamins ineffective in protecting NO from free radical inactivation [99]. Additionally, systemic chronic inflammation may accelerate aging due to reactive oxygen species-mediated exacerbation of telomere dysfunction and cell senescence [107]. Natural antioxidants such as vitamins $\mathrm{C}$ and $\mathrm{E}$, the beneficial components of fruits and vegetables, may exert toxic prooxidant activities at higher doses or under certain conditions [98], vitamin E being able to depress myocardial function [108]. Alpha-tocopherol may suppress other fat soluble, more powerful antioxidants such as gammatocopherol, increasing vulnerability to oxidative damage [109]. Miller III et al. concluded, in a meta-analysis, that there is a dose-dependent relationship between vitamin $\mathrm{E}$ supplementation and all-cause mortality and that high doses of vita$\min \mathrm{E}(\geq 400 \mathrm{IU})$ may increase all-cause mortality and should be avoided [97]. All-cause mortality progressively increased for doses exceeding $150 \mathrm{IU} /$ day, substantially lower than the tolerable upper intake level for vitamin E (1,500 IU natural or 1,100 IU of synthetic vitamin E) [97]. No relation was observed between brachial-ankle PWV and alpha-tocopherol in a study including 178 Japanese male workers [110].

Shargorodsky et al. demonstrated that combined antioxidant supplementation with vitamins C and E, coenzyme Q10, and selenium improves glucose and lipid metabolism, blood pressure, and arterial compliance in patients with at least 2 cardiovascular risk factors [16].

In the study of Veringa et al., 93 patients with chronic kidney disease received pravastatin, vitamin $\mathrm{E}$, and homocysteine lowering therapy, resulting in significant improvement of arterial compliance and distensibility, but the effect of vitamin $\mathrm{E}$ is not clear because it was combined with pravastatin [40].

Vucinovic et al. demonstrated that the acute intake of an antioxidant cocktail, including vitamins $\mathrm{C}$ and $\mathrm{E}$, preserved bioavailability of $\mathrm{NO}$ and vascular function against hyperoxia-induced oxidative stress [37] (Table 3). Combined supplementation of vitamins $\mathrm{C}$ and $\mathrm{E}$ was ineffective in improving endothelial function in 14 randomized trials, including 597 participants, regardless of age, duration, dose, or baseline plasma concentration of vitamins [99]. Park et al. demonstrated that higher intake of beta-carotene, vitamins $C$, $\mathrm{E}$, and folate may protect individuals genetically vulnerable to stiffening of the arteries, in a study including 3,198 healthy men and women from the Korea Multirural communities, quantifiyng dietary intakes by a food frequency questionnaire [111].

Concluding, vitamin E supplementation is supposed to decrease arterial stiffness due to its antiatherogenic and antioxidant effects and the ability to restore endothelial function, but its prooxidant effect must be considered at higher doses. Meta-analyses failed to confirm the role of antioxidant supplementation in primary and secondary cardiovascular prevention and recommend combined use of antioxidants [112]. Several limitations have been noticed in studies evaluating the effect of antioxidant vitamins on arterial stiffness and cardiovascular risk, such as a small sample size, heterogenous study populations, lack of objective criteria to include participants as healthy, differences in definition criteria of patients who are potential candidates for antioxidant therapy, different type and dosage of antioxidants, low correlations between dietary vitamins $\mathrm{C}$ and $\mathrm{E}$ intake, and plasma levels, reflecting the innacuracy of dietary questionnaires in the assessment of intake, individual variations in vitamin absorption and metabolism, missing plasma levels of antioxidants, and data regarding treatment compliance $[16,102,108]$. When excluding small studies (with less than 20 participants), antioxidant vitamin supplementation in larger studies significantly decreased arterial stiffness [102].

\section{Vitamin C}

Ascorbic acid is the cofactor of hydroxyproline synthesis, stabilizing the triple helix structure of collagen. Vitamin C is also a potent water-soluble antioxidant, enabling scavenging of superoxide anions and other reactive oxygen species [38], and prevents LDL oxidation, through recycling of alphatocopherol or by directly scavenging free radicals [46]. Arterial stiffness is impaired by oxidative stress and negative correlations were obtained between PWV and superoxide dismutase level [113]. PWV was dependent on the free radi$\mathrm{cal} /$ antioxidant Redox balance and nitric oxide bioavailability in patients with chronic obstructive pulmonary disease, and PWV increased after an antioxidant cocktail including vitamins $\mathrm{C}$ and E and alpha-lipoic acid [39] (Table 3). Results of antioxidant using trials, as an intervention in cardiovascular disease, have been mixed, but it is important to mention that most trials used a single antioxidant. Kelly et al. reported no effect of a single dose of oral vitamin $C$ on augmentation index and several markers of oxidative stress, including DNA base oxidation products, in 26 healthy volunteers [42]. On the other hand, Katayama et al. suggested that oral vitamin $\mathrm{C}$ administration prevents smoking-induced acceleration in arterial stiffness through reducing endothelial dysfunction, but 


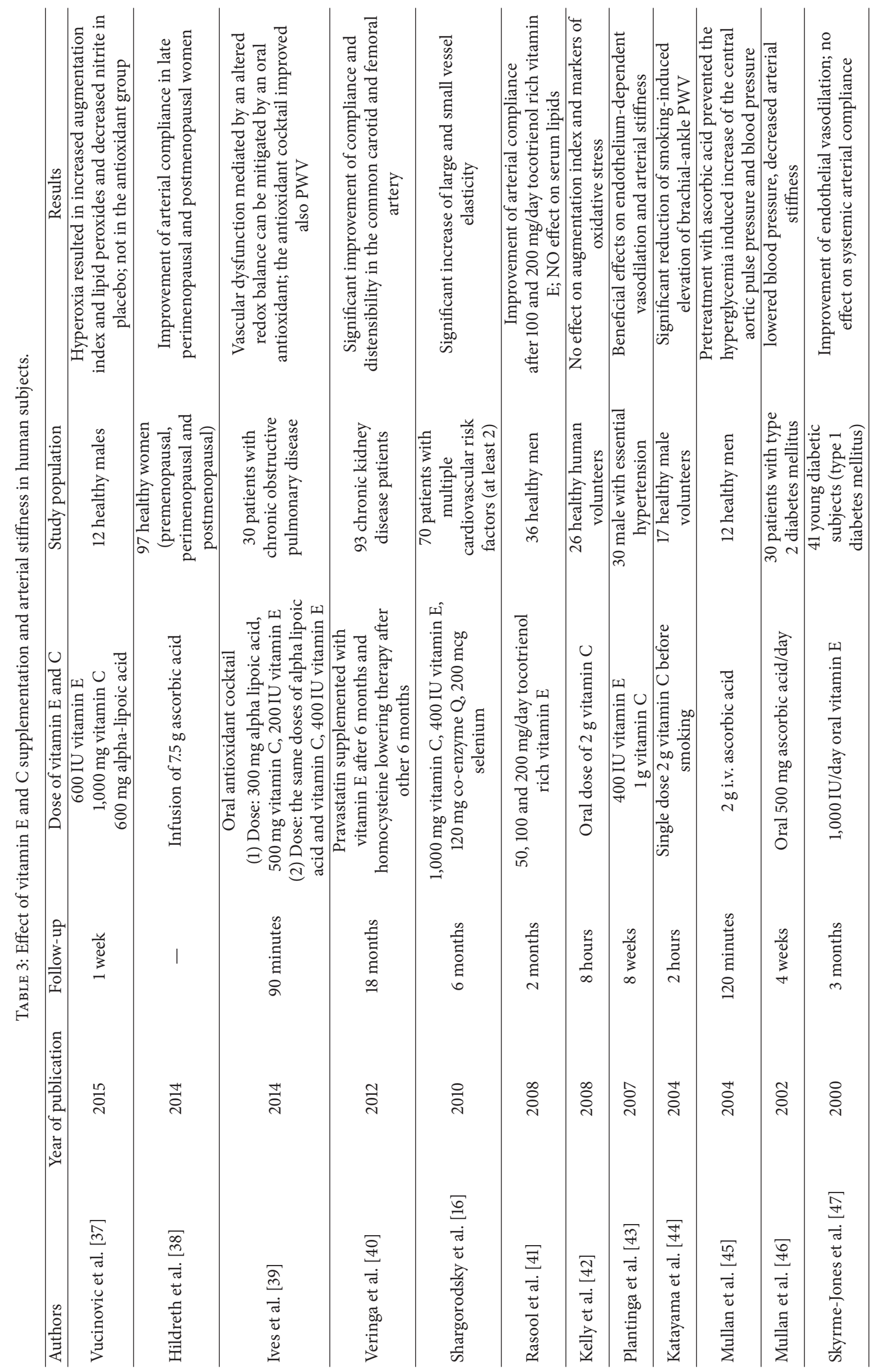


does not influence heart rate and blood pressure [44]. The long-term effect in smokers is not beneficial on endothelial function [114] and smoking negatively influenced vitamin C level [115]. The use of an antioxidant cocktail, containing both water and fat soluble vitamins, seems to be more beneficial for vascular stiffness [39]. Acute administration of vitamin C has also been previously reported to lower augmentation index in healthy volunteers [116].

Peripheral and central hemodynamic changes noticed in acute systemic hyperglycemia, may be prevented or attenuated by pretreatment with a $2 \mathrm{~g}$ intravenous bolus of ascorbic acid according to a study including 12 healthy men [45]. Ascorbic acid may reverse impaired endotheliumdependent NO-mediated vasodilation in several conditions, including acute hyperglycemia and chronic renal failure [45, 117]. The main mechanisms of NO increase include reduced NO degradation by free radicals considering ascorbic acid, as an extremely potent free radical scavenger, increase of endothelial NO synthase activity, increase in the intracellular content of tetrahydrobiopterin, reduced insulin resistance, or smooth muscle sensitivity to NO $[45,46,116,118,119]$. Diabetes mellitus is associated with endothelial dysfunction due to several factors, including hyperglycemia, insulin resistance, hyperlipidemia, oxidized LDL and ascorbic acid deficiency (due to an impaired vitamin $\mathrm{C}$ recycling), and arterial stiffness [46]. Oral administration of $500 \mathrm{mg}$ ascorbic acid/day, for 4 weeks, reduced arterial stiffness in diabetic patients, suggesting a functional change, probably due to increased NO [46].

Vitamins $\mathrm{C}$ and $\mathrm{E}$ increased the collagen content of the arterial wall and reduced vascular metalloproteinase-1, which explains their role in the structural remodeling of the vessel wall and stabilizing the atherosclerotic plaque [100].

Stiffening of large arteries increases progressively during menopause, mediated by estrogen deficiency, oxidative stress, and reduction of NO bioavailability [38]. Infusion of supraphysiological doses of ascorbic acid increased carotid artery compliance in late perimenopausal and postmenopausal women, but not in premenopausal women; the carotid artery compliance was not restored to premenopausal levels [38]. Late perimenopause is associated with changes in lipid metabolism and cardiovascular risk factors, known amplifiers of oxidative stress and arterial stiffening $[38,120]$. Incomplete suppression of reactive oxygen species (ROS) by ascorbic acid and involvement of other sources of ROS, such as peroxynitrite, could explain why artery compliance was not restored to premenopausal levels [38].

High doses of vitamin $\mathrm{C}$ may have a prooxidant effect [98] and may impair arterial stiffness. On the other hand, only supraphysiological concentrations of ascorbate may prevent the interaction of superoxide and nitric oxide [46, 121]. Higher vitamin C levels were associated with lower levels of inflammatory markers, fasting blood glucose, and improved endothelial function $[108,122]$. Supplementation with vitamin $\mathrm{C}$ alone improved endothelial function, especially in study participants older than 56 years; no significant modifying effects of the dose or duration of vitamin C supplementation on endothelial function were found [99]. Older people are more likely to have inadequate micronutrient intakes and absorption and greater oxidative stress due to age-related mitochondrial dysfunction, with a greater benefit from vitamin C supplementation [99].

Concluding, vitamin $\mathrm{C}$ supplementation may reduce arterial stiffness by stabilizing the atherosclerotic plaque and its antoxidant and anti-inflammatory effect and by improving endothelial function.

\section{Vitamin A}

Vitamin A includes several organic compounds, such as retinol, retinoic acid, and carotenoids (lycopene, lutein/ zeaxanthin, beta-carotene, alpha-carotene, and beta-cryptoxanthin). Besides vitamin A importance in good vision and immune system, it is included in the group of antioxidant vitamins [102]. High serum concentrations of carotenoids, abundant in many fruits and vegetables, associated with the Mediterranean diet, may be protective against early atherosclerosis, by inhibiting LDL oxidation [123, 124]. High serum concentrations of lycopene and alpha- and betacarotene were associated with reduced intima-media thickness progression during 7-year follow-up. Vessel walls of carotid arteries were more elastic in subjects whose diets were rich in carotenoids according to the ARIC study [125]. Rissanen et al. found also low plasma lycopene levels associated with early atherosclerosis, manifested as increased intimamedia thickness of the common carotid artery wall, in 520 middle-aged men and women living in eastern Finland [126].

Due to the antioxidant activity that attenuates the inflammatory atherosclerotic process, the carotenoids delay vascular aging due to several mechanisms: their antioxidant activity (that attenuates the inflammatory atherosclerotic process), the ability to increase bioavailability of $N O$, the improvement of the metabolic profile, and their LDL lowering effect [127].

Free radicals, resulting from smoking, deplete serum carotenoid levels, especially alpha- and beta-carotene, lutein/ zeaxanthin, and beta-cryptoxanthin [115]. Vitamin A supplementation may slow progression of atherosclerosis, by reducing the production of the inflammatory cytokine IL-17 and retinoid-related orphan receptor-c gene expression, the main transcriptor factor that controls Th17 cells differentiation [128].

In other words, vitamin A supplementation enables destiffening due to its antioxidant and anti-inflammatory effect and by improving endothelial function and metabolic profile. Carotenoid utilization failed to decrease the rate of major cardiovascular events in randomized trials, and their role in secondary cardiovascular prevention is not clear [127], but further follow-up studies are needed in order to confirm its importance.

\section{Vitamin B12}

Vitamin B12 (cobalamin) is an essential, water-soluble nutrient, involved in DNA synthesis [19]. Vitamin B12 deficiency, very prevalent in Europe, is caused mainly by vegetarianism and is known to be associated with megaloblastic anemia and neuropathy. Metformin therapy, a first line therapy in type 2 
TABLE 4: Effect of vitamin B12 supplementation on arterial stiffness in human subjects.

\begin{tabular}{lccccc}
\hline Authors & $\begin{array}{c}\text { Year of } \\
\text { publication }\end{array}$ & Follow-up & Dose of vitamin B12 & Study population & Results \\
\hline Van Dijk et al. [48] & 2015 & 2 years & $500 \mu \mathrm{g} \mathrm{B12} \mathrm{vitamin}$ & $\begin{array}{c}569 \text { hyperhomocystenemic } \\
\text { elderly }\end{array}$ & $\begin{array}{c}\text { No effect on PWV or } \\
\text { carotid intima-media } \\
\text { thickness }\end{array}$ \\
\hline Koyama et al. [49] & 2010 & 3 weeks & $\begin{array}{c}500 \text { mug methylcobalamin } \\
\text { and 15 mg/day folate } 3 \\
\text { times weekly }\end{array}$ & $\begin{array}{c}\text { 20 patients undergoing } \\
\text { hemodialysis }\end{array}$ & Decreased arterial stiffness \\
\hline
\end{tabular}

diabetes mellitus, reduces the circulating B12 levels by $25 \%$ [129].

Several studies investigated the effect of vitamin B12 level and supplementation and cardiovascular health and arterial stiffness. Previous results suggested also associations between vitamin B12 level and adverse serum lipid profiles in patients with type 2 diabetes mellitus, especially with triglycerides and cholesterol/HDL ratio, due to inhibition of carnitine palmitoyl transferase, the rate-limiting enzyme of fatty acid oxidation [129]. Vitamin B12 deficiency caused also elevation of homocysteine, a risk factor for cardiovascular disease, by inhibiting its conversion to methionine [19]. It has been hypothesized that low B12 vitamin increases cardiovascular risk, partly through direct effects [130].

$\mathrm{Su}$ et al. found no significant differences of arterial function parameters between postmenopausal vegetarians and omnivores [131]. Just brachial artery resistance was lower in vegetarians [131].

Van Dijk et al. did not report any effect of vitamin B12 and folic acid supplementation on PWV or carotid intimamedia thickness in hyperhomocysteinemic elderly patients [48] (Table 4).

Koyama et al. found decreased arterial stiffness, associated with decreased serum asymmetric dimethylarginine in 20 patients undergoing hemodialysis after supplementation with folate and methylcobalamin [49]. Vitamin B12 levels were marginally associated with PWV in 86 patients with diabetes mellitus [132].

Vitamin B12 supplementation enables destiffening by improving the lipid profile and reducing the homocysteine level. A systematic review of cohort studies concluded that current data do not support vitamin B12 supplementation to reduce cardiovascular risk [130]. Further long-term followup studies should focus on specific populations in order to confirm destiffening through vitamin B12 supplementation, not just in patients undergoing hemodialysis.

\section{Conclusions}

There is a complex relationship between vitamin status and arterial stiffness, and each vitamin has specific effects on the vascular wall. Vitamin supplementation may be an effective and inexpensive adjunctive therapy in several conditions associated with increased arterial stiffness and they should be implemmented in patients' diet, considering individual vitamin status.
Vitamin D deficiency, involved in the pathophysiology of cardiovascular disease, may be an important therapeutic target. Despite heterogeneity and conflicting results of trials on vitamin D supplementation, arterial stiffness was significantly decreased in children with chronic kidney disease, black adolescents, adults with vitamin D deficiency with or without prehypertension, nondiabetic patients with hyperglycemia or positive diabetes score, and type 2 diabetic patients with nephropathy. Further large, randomized, evidence based, follow-up studies, including subjects with several other disorders, will demonstrate if vitamin $\mathrm{D}$ level is a marker of subclinical atherosclerosis, an effective target in cardiovascular prevention, therapy, destiffening, and vascular protection, or just a marker of poor health status, and which is the most effective form and level of vitamin $\mathrm{D}$.

Vitamin K was beneficial in decreasing arterial stiffness in healthy postmenopausal women, patients with a history of vascular or coronary artery disease, vitamin $\mathrm{E}$ in subjects with type 1 diabetes mellitus and chronic kidney disease, and vitamin $\mathrm{C}$ in smokers, late perimenopausal, and postmenopausal women, and patients with type 2 diabetes mellitus. The combination including vitamin $\mathrm{C}$ and $\mathrm{E}$ could play an important role in cardiovascular disease prevention in young participants with lower baseline plasma levels, resulting in decreased arterial stiffness in patients with chronic obstructive pulmonary disease and essential hypertension. Further studies are needed in order to explore the effect of vitamin A supplementation on arterial stiffness, considering the antioxidant effect of vitamin A, its effect on endothelial function, metabolic profile, and its anti-inflammatory effect. Vitamin B12 supplementation was demonstrated to reduce arterial stiffness in patients undergoing hemodialysis.

The divergent results and mismatch between epidemiological and interventional studies warrant further investigation, but vitamins A, B12, D, K, C, and E may be markers of arterial stiffness and cardiovascular health. Cardiovascular prevention guidelines should consider and include trials with positive results. Vitamin $\mathrm{K} 2$ and low dose vitamin D have promising potential for prevention of vascular calcification. The potential public health importance of vitamin level and supplementation remains to be further tested in stratified intervention studies, and future research should focus on optimal vitamin levels and identifying patients who would benefit most from vitamin supplementation in order to enable individualized therapy, a personalised approach, and early interventions in primary, but also secondary prevention of cardiovascular disease. 


\section{Competing Interests}

The authors declare that there is no conflict of interests regarding the publication of this paper.

\section{References}

[1] J. L. Cavalcante, J. A. C. Lima, A. Redheuil, and M. H. Al-Mallah, "Aortic stiffness: current understanding and future directions," Journal of the American College of Cardiology, vol. 57, no. 14, pp. 1511-1522, 2011.

[2] N. Nordstrand, E. Gjevestad, J. K. Hertel et al., "Arterial stiffness, lifestyle intervention and a low-calorie diet in morbidly obese patients-a nonrandomized clinical trial," Obesity, vol. 21, no. 4, pp. 690-697, 2013

[3] Y. Ben-Shlomo, M. Spears, C. Boustred et al., "Aortic pulse wave velocity improves cardiovascular event prediction: an individual participant meta-analysis of prospective observational data from 17,635 subjects," Journal of the American College of Cardiology, vol. 63, no. 7, pp. 636-646, 2014.

[4] H. Stricker, F. Tosi Bianda, S. Guidicelli-Nicolosi, C. Limoni, and G. Colucci, "Effect of a single, oral, high-dose vitamin D supplementation on endothelial function in patients with peripheral arterial disease: a randomised controlled pilot study," European Journal of Vascular and Endovascular Surgery, vol. 44, no. 3, pp. 307-312, 2012.

[5] A. R. Patange, R. P. Valentini, W. Du, and M. D. Pettersen, "Vitamin D deficiency and arterial wall stiffness in children with chronic kidney disease," Pediatric Cardiology, vol. 33, no. 1, pp. 122-128, 2012.

[6] C. Vlachopoulos, K. Aznaouridis, M. F. O’Rourke, M. E. Safar, K. Baou, and C. Stefanadis, "Prediction of cardiovascular events and all-cause mortality with central haemodynamics: a systematic review and meta-analysis," European Heart Journal, vol. 31, no. 15, pp. 1865-1871, 2010.

[7] H. H. Dao, R. Essalihi, C. Bouvet, and P. Moreau, "Evolution and modulation of age-related medial elastocalcinosis: impact on large artery stiffness and isolated systolic hypertension," Cardiovascular Research, vol. 66, no. 2, pp. 307-317, 2005.

[8] M. Doyon, P. Mathieu, and P. Moreau, "Decreased expression of $\gamma$-carboxylase in diabetes-associated arterial stiffness: impact on matrix Gla protein," Cardiovascular Research, vol. 97, no. 2, pp. 331-338, 2013.

[9] W. Karwowski, B. Naumnik, M. Szczepański, and M. Myśliwiec, "The mechanism of vascular calcification - a systematic review," Medical Science Monitor, vol. 18, no. 1, pp. RA1-RA11, 2012.

[10] J. H. O'Keefe, N. Bergman, P. Carrera-Bastos, M. FontesVillalba, J. J. DiNicolantonio, and L. Cordain, "Nutritional strategies for skeletal and cardiovascular health: hard bones, soft arteries, rather than vice versa," Open Heart, vol. 3, no. 1, Article ID e000325, 2016.

[11] M. S. El Asmar, J. J. Naoum, and E. J. Arbid, "Vitamin K dependent proteins and the role of vitamin K2 in the modulation of vascular calcification: a review," Oman Medical Journal, vol. 29, no. 3, pp. 172-177, 2014.

[12] R. C. Johnson, J. A. Leopold, and J. Loscalzo, "Vascular calcification. Pathobiological mechanisms and clinical implications," Circulation Research, vol. 99, no. 10, pp. 1044-1059, 2006.

[13] C. M. Shanahan, M. H. Crouthamel, A. Kapustin, and C. M. Giachelli, "Arterial calcification in chronic kidney disease: key roles for calcium and phosphate," Circulation Research, vol. 109, no. 6, pp. 697-711, 2011.
[14] A. Waśkiewicz, D. Szcześniewska, D. Szostak-Węgierek et al., "Are dietary habits of the Polish population consistent with the recommendations for prevention of cardiovascular disease?WOBASZ II Project," Kardiologia Polska, vol. 74, no. 9, pp. 969977, 2016.

[15] M. Zureik, P. Galan, S. Bertrais et al., "Effects of long-term daily low-dose supplementation with antioxidant vitamins and minerals on structure and function of large arteries," Arteriosclerosis, Thrombosis, and Vascular Biology, vol. 24, no. 8, pp. 14851491, 2004.

[16] M. Shargorodsky, O. Debby, Z. Matas, and R. Zimlichman, "Effect of long-term treatment with antioxidants (vitamin C, vitamin E, coenzyme Q10 and selenium) on arterial compliance, humoral factors and inflammatory markers in patients with multiple cardiovascular risk factors," Nutrition \& Metabolism, vol. 7, article 55, 2010.

[17] R. Estruch, E. Ros, J. Salas-Salvadó et al., "Primary prevention of cardiovascular disease with a Mediterranean diet," The New England Journal of Medicine, vol. 368, no. 14, pp. 1279-1290, 2013.

[18] C. McGreevy and D. Williams, "New insights about vitamin $\mathrm{D}$ and cardiovascular disease: a narrative review," Annals of Internal Medicine, vol. 155, no. 12, pp. 820-826, 2011.

[19] X. Mao, X. Xing, R. Xu et al., "Folic acid and vitamins D and B12 correlate with homocysteine in chinese patients with type2 diabetes mellitus, hypertension, or cardiovascular disease," Medicine, vol. 95, no. 6, Article ID e2652, 2016.

[20] L. Schwingshackl, G. Hoffmann, B. Buijsse et al., "Dietary supplements and risk of cause-specific death, cardiovascular disease, and cancer: a protocol for a systematic review and network meta-analysis of primary prevention trials," Systematic Reviews, vol. 4, article no. 34, 2015.

[21] N. G. Forouhi, R. K. Menon, S. J. Sharp et al., "Effects of vitamin D2 or D3 supplementation on glycemic control and cardiometabolic risk among people at risk of type 2 diabetes; results of a randomized double-blind placebo-controlled trial," Diabetes, Obesity and Metabolism, vol. 18, no. 4, pp. 392-400, 2016.

[22] M. B. Aytaç, M. Deveci, K. Bek, Ö. Kayabey, and Z. Ekinci, "Effect of cholecalciferol on local arterial stiffness and endothelial dysfunction in children with chronic kidney disease," Pediatric Nephrology, vol. 31, no. 2, pp. 267-277, 2016.

[23] S. Munisamy, K. M. Daud, S. S. Mokhtar, and A. H. G. Rasool, "Effects of $1 \alpha$-calcidol (alfacalcidol) on microvascular endothelial function, arterial stiffness, and blood pressure in type II diabetic nephropathy patients," Microcirculation, vol. 23, no. 1, pp. 53-61, 2016.

[24] A. Zaleski, G. Panza, H. Swales et al., "High-dose versus lowdose vitamin D supplementation and arterial stiffness among individuals with prehypertension and vitamin D deficiency," Disease Markers, vol. 2015, Article ID 918968, 7 pages, 2015.

[25] C. McGreevy, M. Barry, C. Davenport et al., "The effect of vitamin $\mathrm{D}$ supplementation on arterial stiffness in an elderly community-based population," Journal of the American Society of Hypertension, vol. 9, no. 3, pp. 176-183, 2015.

[26] A. D. Gepner, I. V. Haller, D. C. Krueger, C. E. Korcarz, N. Binkley, and J. H. Stein, "A randomized controlled trial of the effects of vitamin D supplementation on arterial stiffness and aortic blood pressure in native American women," Atherosclerosis, vol. 240, no. 2, pp. 526-528, 2015.

[27] O.-H. Ryu, W. Chung, S. Lee, K.-S. Hong, M.-G. Choi, and H. J. Yoo, "The effect of high-dose vitamin D supplementation on 
insulin resistance and arterial stiffness in patients with type 2 diabetes," Korean Journal of Internal Medicine, vol. 29, no. 5, pp. 620-629, 2014.

[28] N. Chitalia, T. Ismail, L. Tooth et al., "Impact of Vitamin D Supplementation on Arterial Vasomotion, Stiffness and Endothelial Biomarkers in Chronic Kidney Disease Patients," PLoS ONE, vol. 9, no. 3, Article ID e91363, 2014.

[29] D. Martins, Y. Meng, N. Tareen et al., "The effect of short term vitamin D supplementation on the inflammatory and oxidative mediators of arterial stiffness," Health, vol. 6, no. 12, pp. 15031511, 2014.

[30] A. Levin, T. Perry, P. De Zoysa et al., "A randomized control trial to assess the impact of vitamin D supplementation compared to placebo on vascular stiffness in chronic kidney disease patients," BMC Cardiovascular Disorders, vol. 14, article 156, 2014.

[31] F. H. Mose, H. Vase, T. Larsen et al., "Cardiovascular effects of cholecalciferol treatment in dialysis patients-a randomized controlled trial," BMC Nephrology, vol. 15, no. 1, article 50, 2014.

[32] B. Klop, G.-J. M. van de Geijn, E. Birnie et al., "Vitamin D3 mediated effects on postprandial leukocyte activation and arterial stiffness in men and women," European Journal of Clinical Nutrition, vol. 68, no. 5, pp. 635-637, 2014.

[33] Y. Dong, I. S. Stallmann-Jorgensen, N. K. Pollock et al., "A 16-week randomized clinical trial of 2000 international units daily vitamin D3 supplementation in black youth: 25Hydroxyvitamin D, adiposity, and arterial stiffness," The Journal of Clinical Endocrinology and Metabolism, vol. 95, no. 10, pp. 4584-4591, 2010.

[34] R. L. Fulton, M. E. T. McMurdo, A. Hill et al., "Effect of vitamin $\mathrm{K}$ on vascular health and physical function in older people with vascular disease-a randomised controlled trial," The Journal of Nutrition, Health \& Aging, vol. 20, no. 3, pp. 325-333, 2016.

[35] M. H. J. Knapen, L. A. J. L. M. Braam, N. E. Drummen, O. Bekers, A. P. G. Hoeks, and C. Vermeer, "Menaquinone7 supplementation improves arterial stiffness in healthy postmenopausal women: a double-blind randomised clinical trial," Thrombosis and Haemostasis, vol. 113, no. 5, pp. 1135-1144, 2015.

[36] L. M. Vossen, L. J. Schurgers, B. J. van Varik et al., "Menaquinone-7 supplementation to reduce vascular calcification in patients with coronary artery disease: rationale and study protocol (VitaK-CAC Trial)," Nutrients, vol. 7, no. 11, pp. 8905-8915, 2015.

[37] Z. Vucinovic, D. Duplancic, A. Seselja-Perisin et al., "Acute application of antioxidants protects against hyperoxia-induced reduction of plasma nitrite concentration," Clinical physiology and functional imaging, vol. 35, no. 1, pp. 76-80, 2015.

[38] K. L. Hildreth, W. M. Kohrt, and K. L. Moreau, "Oxidative stress contributes to large elastic arterial stiffening across the stages of the menopausal transition," Menopause, vol. 21, no. 6, pp. 624632, 2014

[39] S. J. Ives, R. A. Harris, M. A. Witman et al., "Vascular dysfunction and chronic obstructive pulmonary disease: the role of redox balance," Hypertension, vol. 63, no. 3, pp. 459-467, 2014.

[40] S. J. E. Veringa, P. W. B. Nanayakkara, F. J. Van Ittersum et al., "Effect of a treatment strategy consisting of pravastatin, vitamin E, and homocysteine lowering on arterial compliance and distensibility in patients with mild-to-moderate chronic kidney disease," Clinical Nephrology, vol. 78, no. 4, pp. 263-272, 2012.

[41] A. H. G. Rasool, A. R. A. Rahman, K. H. Yuen, and A. R. Wong, "Arterial compliance and vitamin E blood levels with a self emulsifying preparation of tocotrienol rich vitamin E," Archives of Pharmacal Research, vol. 31, no. 9, pp. 1212-1217, 2008.

[42] R. Kelly, K. Poo Yeo, H. Isaac et al., "Lack of effect of acute oral ingestion of vitamin $\mathrm{C}$ on oxidative stress, arterial stiffness or blood pressure in healthy subjects," Free Radical Research, vol. 42, no. 5, pp. 514-522, 2008.

[43] Y. Plantinga, L. Ghiadoni, A. Magagna et al., "Supplementation with vitamins $\mathrm{C}$ and $\mathrm{E}$ improves arterial stiffness and endothelial function in essential hypertensive patients," American Journal of Hypertension, vol. 20, no. 4, pp. 392-397, 2007.

[44] Y. Katayama, H. Shige, A. Yamamoto, F. Hirata, and H. Yasuda, "Oral vitamin C ameliorates smoking-induced arterial wall stiffness in healthy volunteers," Journal of atherosclerosis and thrombosis, vol. 11, no. 6, pp. 354-357, 2004.

[45] B. A. Mullan, C. N. Ennis, H. J. P. Fee, I. S. Young, and D. R. McCance, "Protective effects of ascorbic acid on arterial hemodynamics during acute hyperglycemia," American Journal of Physiology-Heart and Circulatory Physiology, vol. 287, no. 3, pp. H1262-H1268, 2004.

[46] B. A. Mullan, I. S. Young, H. Fee, and D. R. McCance, "Ascorbic acid reduces blood pressure and arterial stiffness in type 2 diabetes," Hypertension, vol. 40, no. 6, pp. 804-809, 2002.

[47] R. A. P. Skyrme-Jones, R. C. O’Brien, K. L. Berry, and I. T. Meredith, "Vitamin E supplementation improves endothelial function in type I diabetes mellitus: a randomized, placebocontrolled study," Journal of the American College of Cardiology, vol. 36, no. 1, pp. 94-102, 2000.

[48] S. C. Van Dijk, A. W. Enneman, K. M. A. Swart et al., "Effects of 2-year vitamin B12 and folic acid supplementation in hyperhomocysteinemic elderly on arterial stiffness and cardiovascular outcomes within the B-PROOF trial," Journal of Hypertension, vol. 33, no. 9, pp. 1897-1906, 2015.

[49] K. Koyama, A. Ito, J. Yamamoto et al., "Randomized controlled trial of the effect of short-term coadministration of methylcobalamin and folate on serum ADMA concentration in patients receiving long-term hemodialysis," American Journal of Kidney Diseases, vol. 55, no. 6, pp. 1069-1078, 2010.

[50] G. Llauradó, A. Megia, A. Cano et al., "FGF-23/vitamin D axis in type 1 diabetes: the potential role of mineral metabolism in arterial stiffness," PLoS ONE, vol. 10, no. 10, Article ID e0140222, 2015.

[51] J. Kaludjerovic and R. Vieth, "Relationship between vitamin D during perinatal development and health," Journal of Midwifery \& Women's Health, vol. 55, no. 6, pp. 550-560, 2010.

[52] M. A. Fouda, I. Z. Turkistani, F. F. Angkaya-Bagayawa et al., "Vitamin D deficiency in young women of childbearing age: the elephant in the room," International Journal of Clinical and Experimental Medicine, vol. 9, no. 2, pp. 4615-4619, 2016.

[53] I. Al Mheid, R. S. Patel, V. Tangpricha, and A. A. Quyyumi, "Vitamin D and cardiovascular disease: is the evidence solid?" European Heart Journal, vol. 34, no. 48, pp. 3691-3698, 2013.

[54] K. Müller and K. Bendtzen, "1,25-dihydroxyvitamin d3 as a natural regulator of human immune functions," Journal of Investigative Dermatology Symposium Proceedings, vol. 1, no. 1, pp. 68-71, 1996.

[55] M. T. Cantorna, L. Snyder, Y.-D. Lin, and L. Yang, "Vitamin D and $1,25(\mathrm{OH})_{2} \mathrm{D}$ regulation of T cells," Nutrients, vol. 7, no. 4, pp. 3011-3021, 2015.

[56] J. Tomson, J. Emberson, M. Hill et al., "Vitamin D and risk of death from vascular and non-vascular causes in the Whitehall study and meta-analyses of 12,000 deaths," European Heart Journal, vol. 34, no. 18, pp. 1365-1374, 2013. 
[57] R. Lieberman, R. P. Wadwa, N. Nguyen et al., “The association between vitamin $\mathrm{D}$ and vascular stiffness in adolescents with and without type 1 diabetes," PloS one, vol. 8, no. 10, p. e77272, 2013.

[58] G. Sypniewska, J. Pollak, P. Strozecki et al., "25-hydroxyvitamin D, biomarkers of endothelial dysfunction and subclinical organ damage in adults with hypertension," American Journal of Hypertension, vol. 27, no. 1, pp. 114-121, 2014.

[59] J. Chang, X.-G. Ye, Y.-P. Hou, J.-L. Wu, S.-L. Li, and Q.-M. Sun, "Vitamin D level is associated with increased left ventricular mass and arterial stiffness in older patients with impaired renal function," Medical Science Monitor, vol. 21, pp. 3993-3999, 2015.

[60] P. Jha, L. M. Dolan, P. R. Khoury, E. M. Urbina, T. R. Kimball, and A. S. Shah, "Low serum vitamin D levels are associated with increased arterial stiffness in youth with type 2 diabetes," Diabetes Care, vol. 38, no. 8, pp. 1551-1557, 2015.

[61] M. C. Sachs, J. D. Brunzell, P. A. Cleary et al., "Circulating vitamin $\mathrm{d}$ metabolites and subclinical atherosclerosis in type 1 diabetes," Diabetes Care, vol. 36, no. 8, pp. 2423-2429, 2013.

[62] S. C. van Dijk, E. Sohl, C. Oudshoorn et al., "Non-linear associations between serum $25-\mathrm{OH}$ vitamin $\mathrm{D}$ and indices of arterial stiffness and arteriosclerosis in an older population," Age and ageing, vol. 44, no. 1, pp. 136-142, 2015.

[63] A. J. Rodríguez, D. Scott, V. Srikanth, and P. Ebeling, "Effect of vitamin D supplementation on measures of arterial stiffness: a systematic review and meta-analysis of randomized controlled trials," Clinical Endocrinology, vol. 84, no. 5, pp. 645-657, 2016.

[64] E. Charitaki and A. Davenport, "Aortic pulse wave velocity in haemodialysis patients is associated with the prescription of active vitamin D analogues," Journal of Nephrology, vol. 27, no. 4, pp. 431-437, 2014.

[65] K. E. Watson, K. Boström, R. Ravindranath, T. Lam, B. Norton, and L. L. Demer, "TGF- $\beta 1$ and 25-hydroxycholesterol stimulate osteoblast-like vascular cells to calcify," Journal of Clinical Investigation, vol. 93, no. 5, pp. 2106-2113, 1994.

[66] S. Mathew, R. J. Lund, L. R. Chaudhary, T. Geurs, and K. A. Hruska, "Vitamin D receptor activators can protect against vascular calcification," Journal of the American Society of Nephrology, vol. 19, no. 8, pp. 1509-1519, 2008.

[67] S. Chen, C. S. Law, and D. G. Gardner, "Vitamin D-dependent suppression of endothelin-induced vascular smooth muscle cell proliferation through inhibition of CDK2 activity," The Journal of Steroid Biochemistry and Molecular Biology, vol. 118, no. 3, pp. 135-141, 2010.

[68] K.-J. Yun and K.-H. Baek, "Is vitamin D supplementation really effective in patients with type 2 diabetes?" The Korean Journal of Internal Medicine, vol. 29, no. 5, pp. 574-576, 2014.

[69] L. J. Hanks, K. Casazza, S. E. Judd, N. S. Jenny, O. M. Gutiérrez, and V. Sanchez-Margalet, "Associations of fibroblast growth factor-23 with markers of inflammation, insulin resistance and obesity in adults," PLOS ONE, vol. 10, no. 3, Article ID e0122885, 2015.

[70] Y. Saito, T. Yamagishi, T. Nakamura et al., "Klotho protein protects against endothelial dysfunction," Biochemical and Biophysical Research Communications, vol. 248, no. 2, pp. 324-329, 1998.

[71] P. M. Timms, N. Mannan, G. A. Hitman et al., "Circulating MMP9, vitamin D and variation in the TIMP-1 response with VDR genotype: mechanisms for inflammatory damage in chronic disorders?" The Quarterly Journal of Medicine, vol. 95, no. 12, pp. 787-796, 2002.
[72] I. Mozos and O. Marginean, "Links between vitamin D deficiency and cardiovascular diseases," BioMed Research International, vol. 2015, Article ID 109275, 12 pages, 2015.

[73] M. J. Shearer and P. Newman, "Metabolism and cell biology of vitamin K," Thrombosis and Haemostasis, vol. 100, no. 4, pp. 530-547, 2008.

[74] J. M. Geleijnse, C. Vermeer, D. E. Grobbee et al., "Dietary intake of menaquinone is associated with a reduced risk of coronary heart disease: the Rotterdam study," The Journal of Nutrition, vol. 134, no. 11, pp. 3100-3105, 2004.

[75] J. W. J. Beulens, M. L. Bots, F. Atsma et al., "High dietary menaquinone intake is associated with reduced coronary calcification," Atherosclerosis, vol. 203, no. 2, pp. 489-493, 2009.

[76] F. Mac-Way, A. Poulin, M. S. I. Utescu et al., "The impact of warfarin on the rate of progression of aortic stiffness in hemodialysis patients: a longitudinal study," Nephrology Dialysis Transplantation, vol. 29, no. 11, pp. 2113-2120, 2014.

[77] L. J. Schurgers, J. Uitto, and C. P. Reutelingsperger, "Vitamin K-dependent carboxylation of matrix Gla-protein: a crucial switch to control ectopic mineralization," Trends in Molecular Medicine, vol. 19, no. 4, pp. 217-226, 2013.

[78] Y.-P. Liu, Y.-M. Gu, L. Thijs et al., "Inactive matrix gla protein is causally related to adverse health outcomes: a mendelian randomization study in a flemish population," Hypertension, vol. 65, no. 2, pp. 463-470, 2015.

[79] D. Proudfoot and C. M. Shanahan, "Molecular mechanisms mediating vascular calcification: role of matrix Gla protein (review article)," Nephrology, vol. 11, no. 5, pp. 455-461, 2006.

[80] E. Pivin, B. Ponte, M. Pruijm et al., "Inactive Matrix Gla-Protein is associated with arterial stiffness in an adult population-based study," Hypertension, vol. 66, no. 1, pp. 85-92, 2015.

[81] O. Mayer Jr., J. Seidlerová, P. Wohlfahrt et al., "Desphosphouncarboxylated matrix Gla protein is associated with increased aortic stiffness in a general population," Journal of Human Hypertension, vol. 30, no. 7, pp. 418-423, 2016.

[82] O. Gungor, F. Kircelli, J. J. Carrero et al., “The effect of immunosuppressive treatment on arterial stiffness and matrix Gla protein levels in renal transplant recipients," Clinical Nephrology, vol. 75, no. 6, pp. 491-496, 2011.

[83] J. Danziger, R. L. Young, M. K. Shea et al., "Vitamin Kdependent protein activity and incident ischemic cardiovascular disease: the multi-ethnic study of atherosclerosis," Arteriosclerosis, Thrombosis, and Vascular Biology, vol. 36, no. 5, pp. 1037-1042, 2016.

[84] M. K. Shea, S. L. Booth, J. M. Massaro et al., "Vitamin K and vitamin D status: associations with inflammatory markers in the Framingham offspring study," American Journal of Epidemiology, vol. 167, no. 3, pp. 313-320, 2008.

[85] Y. Ohsaki, H. Shirakawa, K. Hiwatashi, Y. Furukawa, T. Mizutani, and M. Komai, "Vitamin K suppresses lipopolysaccharideinduced inflammation in the rat," Bioscience, Biotechnology and Biochemistry, vol. 70, no. 4, pp. 926-932, 2006.

[86] S. Krishnan, N. Chawla, M. D. Ezekowitz, and A. J. Peixoto, "Warfarin therapy and systolic hypertension in men with atrial fibrillation," American Journal of Hypertension, vol. 18, no. 12, pp. 1592-1599, 2005.

[87] J. A. Vaccaro and F. G. Huffman, "Phylloquinone (vitamin K1) intake and pulse pressure as a measure of arterial stiffness in older adults," Journal of Nutrition in Gerontology and Geriatrics, vol. 32, no. 3, pp. 244-257, 2013. 
[88] H. M. H. Spronk, B. A. M. Soute, L. J. Schurgers, H. H. W. Thijssen, J. G. R. De Mey, and C. Vermeer, "Tissue-specific utilization of menaquinone- 4 results in the prevention of arterial calcification in warfarin-treated rats," Journal of Vascular Research, vol. 40, no. 6, pp. 531-537, 2003.

[89] L. Schmölz, M. Birringer, and S. Lorkowski, "Complexity of vitamin E metabolism," World Journal of Biological Chemistry, vol. 7, no. 1, article 14, 2016.

[90] M. Maes, S. Weeckx, A. Wauters et al., "Biological variability in serum vitamin E concentrations: relation to serum lipids," Clinical Chemistry, vol. 42, no. 11, pp. 1824-1831, 1996.

[91] E. B. Rimm, M. J. Stampfer, A. Ascherio, E. Giovannucci, G. A. Colditz, and W. C. Willett, "Vitamin E consumption and the risk of coronary heart disease in men," New England Journal of Medicine, vol. 328, no. 20, pp. 1450-1456, 1993.

[92] M. J. Stampfer, C. H. Hennekens, J. E. Manson, G. A. Colditz, B. Rosner, and W. C. Willett, "Vitamin E consumption and the risk of coronary disease in women," The New England Journal of Medicine, vol. 328, no. 20, pp. 1444-1449, 1993.

[93] A. Shirpoor, L. Norouzi, S. Nemati, and M. H. K. Ansari, "Protective effect of vitamin $\mathrm{E}$ against diabetes-induced oxidized LDL and aorta cell wall proliferation in rat," Iranian Biomedical Journal, vol. 19, no. 2, pp. 117-123, 2015.

[94] L. Cominacini, U. Garbin, A. F. Pasini et al., "Antioxidants inhibit the expression of intercellular cell adhesion molecule-1 and vascular cell adhesion molecule-1 induced by oxidized LDL on human umbilical vein endothelial cells," Free Radical Biology and Medicine, vol. 22, no. 1-2, pp. 117-127, 1997.

[95] S. Sugiyama, K. Kugiyama, M. Ohgushi, K. Fujimoto, and H. Yasue, "Lysophosphatidylcholine in oxidized lowdensity lipoprotein increases endothelial susceptibility to polymorphonuclear leukocyte-induced endothelial dysfunction in porcine coronary arteries: role of protein kinase C," Circulation Research, vol. 74, no. 4, pp. 565-575, 1994.

[96] V. W. Bowry, D. Mohr, J. Cleary, and R. Stocker, "Prevention of tocopherol-mediated peroxidation in ubiquinol-10-free human low density lipoprotein," The Journal of Biological Chemistry, vol. 270, no. 11, pp. 5756-5763, 1995.

[97] E. R. Miller III, R. Pastor-Barriuso, D. Dalal, R. A. Riemersma, L. J. Appel, and E. Guallar, "Meta-analysis: high-dosage vitamin E supplementation may increase all-cause mortality," Annals of Internal Medicine, vol. 142, no. 1, pp. 37-46, 2005.

[98] I. M. C. M. Rietjens, M. G. Boersma, L. D. Haan et al., "The prooxidant chemistry of the natural antioxidants vitamin C, vitamin E, carotenoids and flavonoids," Environmental Toxicology and Pharmacology, vol. 11, no. 3-4, pp. 321-333, 2002.

[99] A. W. Ashor, M. Siervo, J. Lara, C. Oggioni, S. Afshar, and J. C. Mathers, "Effect of vitamin C and vitamin E supplementation on endothelial function: a systematic review and meta-analysis of randomised controlled trials," British Journal of Nutrition, vol. 113, no. 8, pp. 1182-1194, 2015.

[100] J. Orbe, J. A. Rodríguez, R. Arias et al., "Antioxidant vitamins increase the collagen content and reduce MMP-1 in a porcine model of atherosclerosis: implications for plaque stabilization," Atherosclerosis, vol. 167, no. 1, pp. 45-53, 2003.

[101] M. Dusinska, A. Kazimirova, M. Barancokova et al., "Nutritional supplementation with antioxidants decreases chromosomal damage in humans," Mutagenesis, vol. 18, no. 4, pp. 371-376, 2003.

[102] A. W. Ashor, M. Siervo, J. Lara, C. Oggioni, and J. C. Mathers, "Antioxidant vitamin supplementation reduces arterial stiffness in adults: a systematic review and meta-analysis of randomized controlled trials," Journal of Nutrition, vol. 144, no. 10, pp. 15941602, 2014.

[103] G. Hampson, S. Edwards, A. Sankaralingam et al., "Circulating concentrations of vitamin $\mathrm{E}$ isomers: association with bone turnover and arterial stiffness in post-menopausal women," Bone, vol. 81, pp. 407-412, 2015.

[104] J. H. Chin, S. Azhar, and B. B. Hoffman, "Inactivation of endothelial derived relaxing factor by oxidized lipoproteins," The Journal of Clinical Investigation, vol. 89, no. 1, pp. 10-18, 1992.

[105] I. B. Wilkinson, J. R. Cockcroft, and D. J. Webb, "Pulse wave analysis and arterial stiffness," Journal of Cardiovascular Pharmacology, vol. 32, supplement 3, pp. S33-S37, 1998.

[106] S. J. Wigg, M. Tare, J. Forbes et al., "Early vitamin E supplementation attenuates diabetes-associated vascular dysfunction and the rise in protein kinase $\mathrm{C}-\beta$ in mesenteric artery and ameliorates wall stiffness in femoral artery of Wistar rats," Diabetologia, vol. 47, no. 6, pp. 1038-1046, 2004.

[107] D. Jurk, C. Wilson, J. F. Passos et al., "Chronic inflammation induces telomere dysfunction and accelerates ageing in mice," Nature Communications, vol. 2, article 4172, 2014.

[108] S. G. Wannamethee, K. R. Bruckdorfer, A. G. Shaper, O. Papacosta, L. Lennon, and P. H. Whincup, "Plasma vitamin C, but not vitamin $\mathrm{E}$, is associated with reduced risk of heart failure in older men," Circulation: Heart Failure, vol. 6, no. 4, pp. 647654, 2013.

[109] S. Devaraj and I. Jialal, "Failure of vitamin E in clinical trials: is gamma-tocopherol the answer?" Nutrition Reviews, vol. 63, no. 8, pp. 290-293, 2005.

[110] T. Okamura, Y. Moriyama, T. Kadowaki, H. Kanda, and H. Ueshima, "Non-invasive measurement of brachial-ankle pulse wave velocity is associated with serum C-reactive protein but not with $\alpha$-tocopherol in Japanese middle-aged male workers," Hypertension Research, vol. 27, no. 3, pp. 173-180, 2004.

[111] C. Y. Park, S. Jung, M. K. Kim et al., "Habitual dietary intake of $\beta$-carotene, vitamin $\mathrm{C}$, folate, or vitamin $\mathrm{E}$ may interact with single nucleotide polymorphisms on brachial-ankle pulse wave velocity in healthy adults," European Journal of Nutrition, vol. 55 , no. 2, pp. 855-866, 2016.

[112] K. Hagymási, A. Egresi, and G. Lengyel, "Antioxidantsantioxidative stress? Facts and questions, 2015," Orvosi Hetilap, vol. 156, no. 47, pp. 1884-1887, 2015.

[113] M. A. Gómez-Marcos, A. M. Blázquez-Medela, L. GamellaPozuelo, J. I. Recio-Rodriguez, L. García-Ortiz, and C. Martínez-Salgado, "Serum superoxide dismutase is associated with vascular structure and function in hypertensive and diabetic patients," Oxidative Medicine and Cellular Longevity, vol. 2016, Article ID 9124676, 8 pages, 2016.

[114] O. T. Raitakari, M. R. Adams, R. J. McCredie, K. A. Griffiths, R. Stocker, and D. S. Celermajer, "Oral vitamin C and endothelial function in smokers: short-term improvement, but no sustained beneficial effect," Journal of the American College of Cardiology, vol. 35, no. 6, pp. 1616-1621, 2000.

[115] W. Wei, Y. Kim, and N. Boudreau, "Association of smoking with serum and dietary levels of antioxidants in adults: NHANES III, 1988-1994," American Journal of Public Health, vol. 91, no. 2, pp. 258-264, 2001.

[116] I. B. Wilkinson, I. L. Megson, H. MacCallum, N. Sogo, J. R. Cockcroft, and D. J. Webb, "Oral vitamin $\mathrm{C}$ reduces arterial stiffness and platelet aggregation in humans," Journal of Cardiovascular Pharmacology, vol. 34, no. 5, pp. 690-693, 1999. 
[117] M. R. Sabri, E. N. Tavana, A. Ahmadi, and A. Gheissari, "Effect of vitamin $\mathrm{C}$ on endothelial function of children with chronic renal failure: an experimental study," Advanced Biomedical Research, vol. 4, no. 1, article 260, 2015.

[118] M. E. Murphy, "Ascorbate and dehydroascorbate modulate nitric oxide-induced vasodilations of rat coronary arteries," Journal of Cardiovascular Pharmacology, vol. 34, no. 2, pp. 295303, 1999.

[119] J.-R. Wu, L.-P. Kao, B.-N. Wu et al., "Buffered L-ascorbic acid, alone or bound to KMUP-1 or sildenafil, reduces vascular endothelium growth factor and restores endothelium nitric oxide synthase in hypoxic pulmonary artery," Kaohsiung Journal of Medical Sciences, vol. 31, no. 5, pp. 241-254, 2015.

[120] K. A. Matthews, L. H. Kuller, K. Sutton-Tyrrell, and Y.-F. Chang, "Changes in cardiovascular risk factors during the perimenopause and postmenopause and carotid artery atherosclerosis in healthy women," Stroke, vol. 32, no. 5, pp. 1104-1110, 2001.

[121] T. S. Jackson, A. Xu, J. A. Vita, and J. F. Keaney Jr., "Ascorbate prevents the interaction of superoxide and nitric oxide only at very high physiological concentrations," Circulation Research, vol. 83, no. 9, pp. 916-922, 1998.

[122] M. S. Ellulu, A. Rahmat, I. Patimah, H. Khaza'Ai, and Y. Abed, "Effect of vitamin C on inflammation and metabolic markers in hypertensive and/or diabetic obese adults: a randomized controlled trial," Drug Design, Development and Therapy, vol. 9, pp. 3405-3412, 2015.

[123] P. Giordano, P. Scicchitano, M. Locorotondo et al., "Carotenoids and cardiovascular risk," Current Pharmaceutical Design, vol. 18, no. 34, pp. 5577-5589, 2012.

[124] J. Karppi, S. Kurl, K. Ronkainen, J. Kauhanen, and J. A. Laukkanen, "Serum carotenoids reduce progression of early atherosclerosis in the carotid artery wall among Eastern Finnish men," PLoS ONE, vol. 8, no. 5, Article ID e64107, 2013.

[125] S. B. Kritchevsky, T. Shimakawa, G. S. Tell et al., "Dietary antioxidants and carotid artery wall thickness: the ARIC study," Circulation, vol. 92, no. 8, pp. 2142-2150, 1995.

[126] T. Rissanen, S. Voutilainen, K. Nyyssönen, R. Salonen, and J. T. Salonen, "Low plasma lycopene concentration is associated with increased intima-media thickness of the carotid artery wall," Arteriosclerosis, Thrombosis, and Vascular Biology, vol. 20, no. 12, pp. 2677-2681, 2000.

[127] T. Wolak and E. Paran, "Can carotenoids attenuate vascular aging?” Vascular Pharmacology, vol. 59, no. 3-4, pp. 63-66, 2013.

[128] A. Mottaghi, S. Ebrahimof, P. Angoorani, and A.-A. SaboorYaraghi, "Vitamin A supplementation reduces IL-17 and RORc gene expression in atherosclerotic patients," Scandinavian Journal of Immunology, vol. 80, no. 2, pp. 151-157, 2014.

[129] A. Adaikalakoteswari, R. Jayashri, N. Sukumar et al., "Vitamin B12 deficiency is associated with adverse lipid profile in Europeans and Indians with type 2 diabetes," Cardiovascular Diabetology, vol. 13, article 129, 2014.

[130] S. B. Rafnsson, P. Saravanan, R. S. Bhopal, and C. S. Yajnik, "Is a low blood level of vitamin B12 a cardiovascular and diabetes risk factor? A systematic review of cohort studies," European Journal of Nutrition, vol. 50, no. 2, pp. 97-106, 2011.

[131] T.-C. Su, P.-L. Torng, J.-S. Jeng, M.-F. Chen, and C.-S. Liau, "Arterial function of carotid and brachial arteries in postmenopausal vegetarians," Vascular Health and Risk Management, vol. 7, no. 1, pp. 517-523, 2011.

[132] M. Shargorodsky, M. Boaz, S. Pasternak et al., "Serum homocysteine, folate, vitamin B12 levels and arterial stiffness in diabetic patients: which of them is really important in atherogenesis?" Diabetes/Metabolism Research and Reviews, vol. 25, no. 1, pp. 70-75, 2009. 


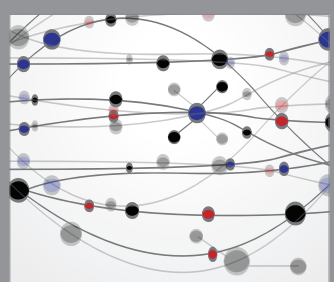

The Scientific World Journal
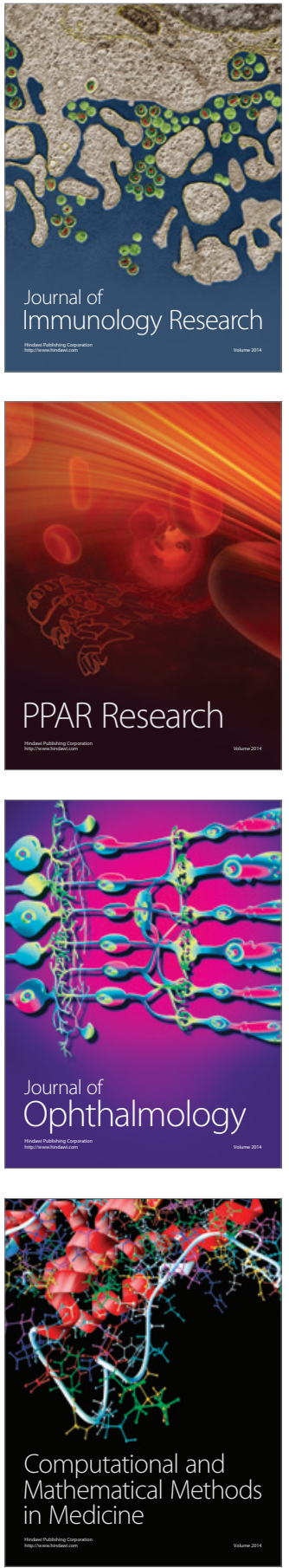

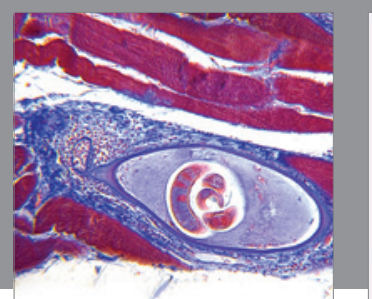

Gastroenterology Research and Practice
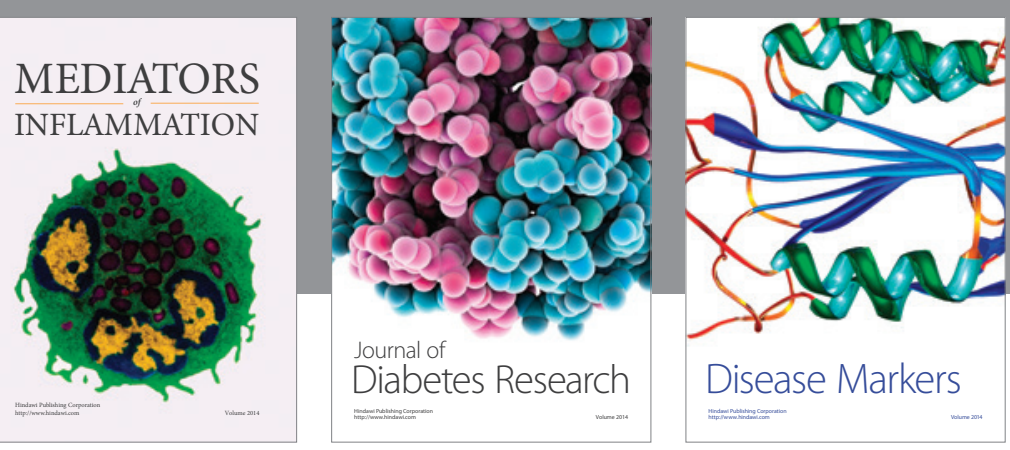

Disease Markers

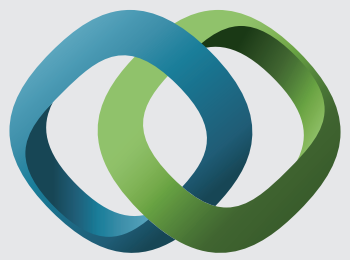

\section{Hindawi}

Submit your manuscripts at

https://www.hindawi.com
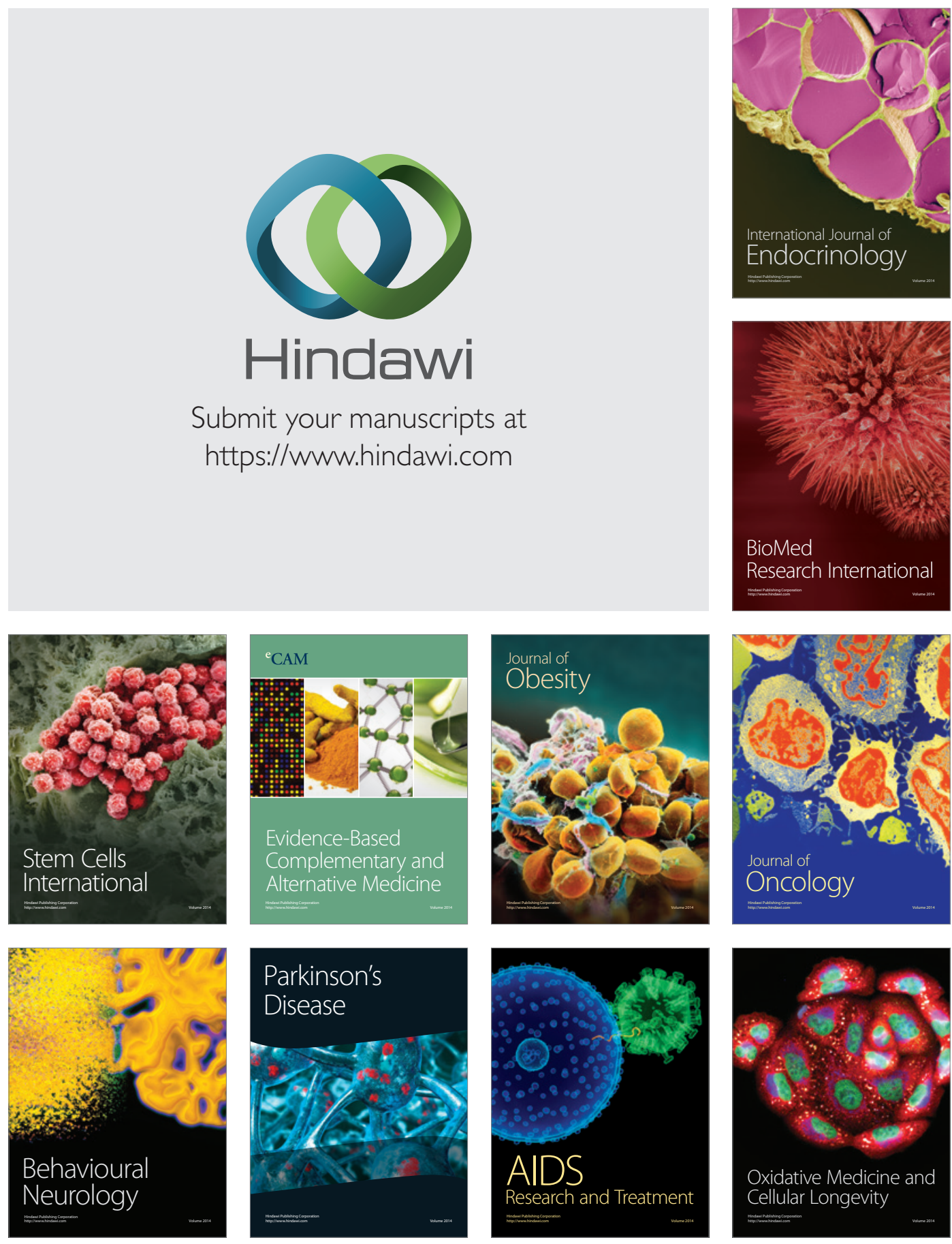